\title{
Hierarchy and the Provision of Order in International Politics
}

\author{
Kyle Beardsley, Duke University \\ Howard Liu, University of Essex \\ Peter J. Mucha, University of North Carolina at Chapel Hill \\ David A. Siegel, Duke University \\ Juan F. Tellez, University of South Carolina
}

\begin{abstract}
The anarchic international system is actually heavily structured: communities of states join together for common benefit; strong states form hierarchical relationships with weak states to enforce order and achieve preferred outcomes. Breaking from prior research, we conceptualize structures such as community and hierarchy as properties of networks of states' interactions that can capture unobserved constraints in state behavior, constraints that may reduce conflict. We offer two claims. One, common membership in trade communities pacifies to the extent that breaking trade ties would entail high switching costs: thus, we expect heavy arms trade, more than most types of commercial trade, to reduce intracommunity conflict. Two, this is driven by hierarchical communities in which strong states can use high switching costs as leverage to constrain conflict between weaker states in the community. We find empirical support for these claims using a timedependent multilayer network model and a new measure of hierarchy based on network centrality.
\end{abstract}

A narchy may continue to be a useful starting point for explaining international politics, but a cursory examination will reveal that states have made much with it. Even in the absence of a legitimate sovereign over the set of nation-states in the current international system, interstate organization is heavily structured. Undergirding this structure is a web of unobserved interests and constraints that guides states' behavior. We record echoes of this web in networks of interstate interactions. These networks capture more than just dyadic behavior: they represent the complex, higherorder interdependencies necessary to understand the behavior of states (Dorff and Ward 2013). For example, explanations of recent relatively stable Israeli-Egyptian relations and volatile Israeli-Syrian relations would be incomplete if they were to solely focus on the domestic politics of Israel, Egypt, and Syria, or even on their pair-wise affinities, to the exclusion of how these states fit within regional and global structures of power.

Different observed networks capture different aspects of the underlying web. ${ }^{1}$ We confine our attention to interstate conflict behavior and two networks that we believe signal states' underlying interests and constraints in this regard- their networks of arms and commercial trade. We further focus on two properties of these networks: the communities present within them and the degree of hierarchy within each community.

Our concept of community captures implicit group membership that is maintained over time. Intuitively, a set of communities is a partition of the set of states in which the volume of trade within each community substantially exceeds the volume between communities. In contrast to explicit instances of group membership, such as formal alliance blocs, the communities that emerge endogenously from our model offer the promise

Kyle Beardsley (kyle.beardsley@duke.edu) is a professor of political science at Duke University, Durham, NC 27701. Howard Liu (haoliu.howard@gmail.com) is a lecturer in the Department of Government at the University of Essex, Colchester, UK. Peter J. Mucha (mucha@unc.edu) is a professor of mathematics and applied physical sciences at the University of North Carolina, Chapel Hill, NC 27599. David A. Siegel (david.siegel@duke.edu) is a professor of political science at Duke University. Juan F. Tellez (TELLEZJ@mailbox.sc.edu) is an assistant professor in political science at the University of South Carolina, Columbia, SC 29208.

Authors listed alphabetically, equal authorship implied. Data and supporting materials necessary to reproduce the numerical results in the article are available in the JOP Dataverse (https://dataverse.harvard.edu/dataverse/jop). An online appendix with supplementary material is available at https://doi.org /10.1086/707096.

1. Using the heuristic provided by Kahler (2009), we focus on networks as structures.

The Journal of Politics, volume 82, number 2. Published online March 31, 2020. https://doi.org/10.1086/707096

(C) 2020 by the Southern Political Science Association. All rights reserved. 0022-3816/2020/8202-0023\$10.00 
of teasing out otherwise hidden patterns that might signal power relationships outside of formal blocs, such as those between the United States and Israel or Egypt, or between Russia and Syria, in addition to relationships between regional powers.

Using trade volume to represent ties also allows us to explore our second network measure, hierarchy, more cleanly than one could with dichotomous ties. Hierarchy, as we define it, is a measure that captures the dispersion of trade volume within a community. Hierarchical communities contain states with substantially unequal contributions to the trade network, while flatter communities comprise more equal trading partners.

Our focus on community and hierarchy enables two main contributions. The first is theoretical: we offer a novel explanation of interstate conflict based on a logic of switching costs and the interaction between community and hierarchy. We argue that trade ties capture not just the volume of trade between states and thus magnitudes of gains from trade but also an array of potential positive and negative inducements between the parties. Cutting a trade tie, even should a similar source for the good in question be found, entails switching costs for the states. The greater these switching costs, the more constrained a state will be in its conflict behavior toward other members of the trading community by the desire to maintain the existing trade network. We claim that the conflict constraint within trading communities will be pronounced when communities are hierarchical (so states that are less central to the trading network will find it especially costly to cut ties with one or a few central states that have incentives to maintain order in the community) and when the good being traded is less fungible (so that states cannot easily switch to another source of the good). This suggests that we should see a reduction in intracommunity conflict in hierarchical arms trade communities over and above what we would expect merely from dyadic trade flows. Below, we elaborate on this expectation and the theory underlying it and find support for it in the empirical analysis.

Second, we contribute new methods to the discipline for calculating community and hierarchy in the international system. With respect to community, we employ a time-dependent multilayer network model that allows us to use both recent and contemporary tie data in community detection. We take advantage of this in constructing joint-production security communities (JPSCs) out of arms-trade data, which betray sufficient temporal variation so as to have hindered prior analysis. ${ }^{2}$ With respect to hierarchy, we introduce a measure

2. We use the "joint-production" modifier to be transparent about a focus on communities based on transactional flows rather than more normative or cultural ties. For work on security communities from more of a sociological perspective, see esp. Adler and Barnett (1998) and Deutsch et al. (1957). that builds on Kinne (2012) to capture a notoriously difficult concept in international relations. The hierarchy measure makes use of information on the weight and directionality of network ties to characterize how asymmetrically distributed the influence of states is within a given community. ${ }^{3}$ Related to the link between network centrality and social power uncovered in earlier scholarship (Hafner-Burton and Montgomery 2009; Lake and Wong 2009), we argue that communities where few (or one) states are highly influential are structured more hierarchically than communities where states share equal influence. This approach can be applied to any weighted network, and we employ it in both arms trade and commercial trade communities. We describe the new model and measure below.

\section{COMMUNITY, HIERARCHY, AND CONFLICT Networks in the international system}

Our theory rests on the idea that underlying the international system is a web of interests and constraints that guide states' behavior. These incentives and constraints might be anything from the pull of shared democratic norms to the rational unwillingness to deviate from strategic optimality. Although the web is unobservable, aspects of it can be inferred from the networks of interstate relations it induces. Examples of such networks are arms or commercial trade, common United Nations voting behavior, intergovernmental organization membership, or conflict and cooperation.

Our focus on networks builds on recent literature that has identified the insufficiency of purely dyadic interactions for understanding interstate behavior (Cranmer and Desmarais 2016; Dorff and Ward 2013; Hoff and Ward 2004). The argument proffered by these and other scholars is that it is not just the existence of a third party that affects dyadic behavior, it is the larger network of interactions that multiple parties engender. There are many ways to incorporate insights from network analysis. ${ }^{4}$ We focus on two summary network properties that are closely tied to our theory: community and hierarchy. ${ }^{5}$

3. See Kinne (2012) for a related approach to measuring centrality in the broader international system.

4. For instance, Cranmer, Desmarais, and Kirkland (2012) use exponential random graph models and Warren $(2010,2016)$ uses stochastic actor models to explore and explain the evolution of alliance networks over time to provide a better understanding of international conflict. Similarly, Kinne (2017) demonstrates that the network of defense cooperation agreements can explain the formation of new bilateral defense cooperation agreements.

5. Summary statistics such as these are viable proxies for the effect of the larger network when they capture the posited theoretical mechanism. For instance, the degree of globalization in a trade network might be productively captured by the density of the network. 


\section{Community}

Our focus on network characteristics begins with one that has been receiving increasing attention in the context of interstate conflict: community membership. Membership in intergovernmental organizations (Greenhill and Lupu 2017), trade (Lupu and Traag 2013), United Nations voting (Pauls and Cranmer 2017), and Kantian (Cranmer, Menninga, and Mucha 2015) communities has been shown to reduce conflict between the states within these communities. ${ }^{6}$ We propose that the same may be true under certain conditions for JPSCs, which are defined on a network comprising the volume of arms trade between states.

To determine membership, one must first derive a set of communities present in a network. A common approach is to identify a network partition that assigns each node in the network - here, each state in the international system - to a single community. ${ }^{7}$ There are many different methods in use to determine the set of communities for a given network, but they all share the same basic intent (Fortunato 2010; Fortunato and Hric 2016; Porter, Onnela, and Mucha 2009). Simply put, states that make up a particular community should have stronger ties to other states within that same community than they do to states outside that community. For our JPSCs, the key idea is that states within each JPSC engage in a much larger volume of arms trade within these communities than between them.

How might membership in a JPSC reduce intracommunity conflict? Consider first a concrete example: the complex relationship between the United States, Egypt, and Israel. In 1979, the United States helped broker a peace treaty between Egypt and Israel. This was the fruit of years of effort that commenced with disengagement after the 1973 October War, still the last war between Egypt and Israel. One of the key carrots that the Americans offered to seal the deal took the form of billions of dollars of annual military aid to both countries, which subsequently has been used to purchase American arms. Effectively, Egypt and Israel have since been participating in the joint production of security with the United States, which is exactly what the United States had hoped would bolster an Egyptian-Israeli détente. Assisted by the United States, Egypt and Israel have been investing in military forces to secure their lands from interstate and intrastate foes. Moreover, their military investments have improved the security of the United States, which has complex security

6. Although see the erratum for Lupu and Traag (2013) at https://github .com/vtraag/trading-communities-replication/commit/e82b76879498d87c5c 2de21c39b13bd7eb96f8a3 regarding trade communities.

7. There are methods that assign membership probabilistically. We use an approach that captures probabilistic membership but typically assigns a node to a single community as detailed below. ties in the region. Purely dyadic approaches to explain conflict behavior are ill suited to capture these observed dynamics, as are approaches that focus on formal alliance ties because the United States does not have a formal alliance with Israel or Egypt.

In this example, sharing the same JPSC translated into less intracommunity conflict, but what are the mechanisms by which common JPSC membership might do so in general? Prior work has posited that interdependence increases the opportunity costs for conflict (Hegre, Oneal, and Russett 2010; Lupu and Traag 2013; Mansfield and Pevehouse 2000), the ability for states to make costly signals (Gartzke 2007; Kinne 2013, 2014), and external vested interests in peace (Lupu and Traag 2013). Certainly, JPSC membership might have all the same effects. Conflict could result in the loss of valuable arms trade, JPSCs might increase transparency due to common use of weapons systems and available costly signals, and third parties might desire to prevent armed conflict among common buyers and suppliers. More generally, arms transfers indicate the extent to which, at minimum, the supplier does not see the buyer as a threat and, at maximum, the supplier finds it mutually beneficial to invest in the buyer's security. In this way, we might infer that states that have strong ties to one another via arms transfers have the potential to develop (or are already undertaking) robust joint security production.

We can also draw on the alliance formation literature. Kinne (2017) shows that states form explicit defense cooperation agreements as a response to a common threat, and Kinne (2016) shows that defense cooperation agreements well explain the flow of arms transfers. Arms trade is thus an element of the joint production economy of security (Lake 1999), one that underlies informal alliances, such as those between the United States and Israel or between Russia and Syria. Regardless of whether the alliance is formal or informal, the goal of participating is the same: to pool resources and take advantage of comparative advantages in security production (Deutsch et al. 1957; Walt 1990). This can lead to reductions in intracommunity conflict: formal alliance commitments enable member states to coordinate behavior, overcome bargaining problems, and reduce the potential for conflict among one another (Bearce, Flanagan, and Floros 2006; Fang, Johnson, and Leeds 2014; Long, Nordstrom, and Baek 2007; Mattes and Vonnahme 2010; Pressman 2008; Weitsman 2004). JPSC membership, which overlaps with formal as well as informal alliances, can have a similar effect. ${ }^{8}$

8. It may be possible that strong JPSCs would lead to increases in intercommunity conflict, as improved security production can threaten states outside the community, potentially leading to a security dilemma spiral 
While these arguments in favor of a pacifying withincommunity effect of common JPSC membership are compelling, we take a more nuanced view of the role of community membership for two reasons. First, there are potentially countervailing effects to some arguments. For example, frequent interactions within the community may themselves lead to more occasions for dispute (Starr 2002) and relevance of relative gains (Barbieri 1996, 2002). And the ex ante costs of conflict may already be built into the demands of challengers and the willingness of targets to concede and thus may not affect the efficiency of conflict bargaining (Morrow 1999).

Second, if common membership in a community is to matter in explaining interstate conflict, it must capture a latent relationship among the states in a community beyond that present in individual states' dyadic relationships. With respect to the existing literature, common community membership may proxy for common preferences (Pauls and Cranmer 2017), mutual opportunities that could be lost if fighting were to arise (Lupu and Traag 2013), or synergies arising from alliance obligations (Cranmer et al. 2012). We argue that under certain circumstances common JPSC membership can proxy for a latent network of constraints on states' conflict behavior. ${ }^{9}$ Making this argument requires first specifying the incentives of states to form and maintain the observable network connections from which communities are created.

Why might states engage in the trade of heavy weapons with the same partners? ${ }^{10}$ The simplest answer is for suppliers' profit and buyers' security. This ignores, however, the degree to which the trade partners would experience switching costs were they to cut ties. Any state that would find it costly to search for a new trading partner potentially faces constraints on its behavior arising from the existence of the tie, in that its trading partner may decide to use maintenance of the tie as leverage to extract concessions. In contrast, the trade ties of states that can both easily and cheaply transfer ties to alternatives are far more difficult to use as leverage, suggesting lesser constraint on these states.

We argue that the trade of heavy arms entails substantial switching costs, particularly, although not exclusively, on the side of buyers. Buying into weapons systems can necessitate a further spate of supporting purchases, including services (Kinsella 1998). Heavy arms are not interchangeable across

(Snyder 1984, 2007), although it is important to note that these processes are jointly endogenous and thus complex to analyze (Smith 1995). We consider this question empirically below without offering strong theoretical expectations.

9. In probing the meaning of the network of ties in the arms trade, we are responding to the call of Kinsella and Montgomery (2016).

10. Our theoretical and empirical focus is on the trade of heavy weapons; the argument is not likely to extend to the trade of light arms. manufacturers, and the transaction costs to shift suppliers are high - it would require major adjustments to personnel training, maintenance procedures, and acquisition of replacement parts, not to mention the replacement of expensive munitions for relevant weapons systems. For these reasons, and in part maintained by heavy offsets by the suppliers to the buyers, the arms trade marketplace remains oligopolistic, as five suppliers - the United States, Russia, United Kingdom, France, and China-account for $80 \%$ of the trade (Markusen 2004; Stohl and Grillot 2009). In this vein, Thurner et al. (2019) use random-graph network models to show that the arms trade is dominated by a few sellers and that buyers typically only buy from one seller. Indeed, supplier states are often motivated to engage in arms transfers because of the leverage gained from the dependence that buyer states develop, and they worry that the growth of the number of suppliers in the international market in the post-Cold War era might threaten the political coin of arms transfers (Caverley 2017; Cornish 1996; Keller 1995). In other words, high switching costs on the part of buyers induce political leverage sellers can use to constrain buyers' behavior in ways favorable to sellers, which includes reduction of destabilizing intracommunity conflict that would not enhance sellers' interests.

Sellers also face switching costs; buyers do occasionally switch suppliers or develop their own domestic production capacity, which can constrain suppliers (Brauer 2003; Keller 1995). While we view these costs as lower, all else equal, than those faced by buyers given the larger number of potential buyers, any level of asset specificity (viewing the trade tie as the asset) would also constrain the seller's actions. So, in total, we expect the arms trade network to capture underlying networks of mutual (although asymmetric) constraint. ${ }^{11}$

11. We might consider defining our JPSCs using other ties as additional inputs into the community detection algorithm, as do Cranmer et al. (2015). Foremost, explicit alliances and defense cooperation agreements clearly indicate an intention for states to jointly contribute to one another's security. Indeed, we demonstrate below that joint membership in JPSCs based on explicit defense cooperation agreements results in similar conflictreducing behavior as the JPSCs based on arms transfers, which is not surprising given that Kinne (2016) finds that weapons cooperation agreements are associated with greater flows in arms transfers. (For definitions of and data on defense cooperation agreements, see Kinne [2016, 2017].) We use the arms-transfer inputs in our core analyses for two reasons. First, one might expect more of a conflict-reducing effect from alliances and defense cooperation agreements, in that they capture explicit pledges for security cooperation. This could leave relatively little independent role for community membership in predicting conflict reduction. In general, the advantage of using community detection on network data is to be able to uncover more embedded relationships that arise from the notion that community membership can be quite latent. Because arms transfers are shaped by market competition among large multinational arms manufacturers that might not well be explained by explicit attempts by states to 
H1. All else equal, JPSCs will have a constraining effect on intracommunity conflict.

It is important to note that the latent network of constraint is present in JPSCs but not to the same extent in communities formed from commercial trade networks. We expect, with some exceptions, commercial trade to be more fungible than trade in heavy arms, so that commercial trade network communities capture far less well the web of unobserved constraints between states that we posit leads to less conflict within communities. In contrast, both types of communities capture to some extent the loss of mutual economic opportunities cutting trade ties will bring. This dynamic suggests that arms sales might pacify better than other types of connection between states.

\section{Hierarchy}

Our first hypothesis specifies an all-else-equal condition, but our specific mechanism of switching costs allows us to dig a bit deeper into variation across JPSCs in their ability to constrain conflict. We focus our attention on a network measure that we argue captures the presence of increased switching costs within a community: the community's level of hierarchy.

How does hierarchy relate to expectations of order within JPSCs? Some forms of joint security production are more hierarchical in the sense that one of the parties has more authority to make decisions concerning the joint production economy. Building on his earlier work, Lake (2009) develops a relational theory of hierarchy in which states will often confer some degree of legitimate authority on a dominant state in return for an expectation of security and order. This understanding of hierarchy has roots in social contract theory, in which actors grant another actor authority in return for a stream of public goods such as security. ${ }^{12}$ A crucial feature of hierarchy is that the power imbalance of the dominant actors over the subordinate actors is legitimated by the common understanding that all actors stand to benefit from the relationship.

Our conceptualization of hierarchy matches Lake's in many substantive ways. However, we diverge from Jung and

enhance the security of their key allies, they provide an interesting venue to test the potential value added for considering community membership in addition to bilateral commitments. Second, arms transfers are directional and nonbinary and thus provide a richer ability to consider the strength of ties and the direction of dependence, which are important components of our definition of hierarchy, described in more detail below.

12. See also Lake and Wong (2009). Mattern and Zarakol (2016) describe a number of logics by which hierarchy might shape international relations, and our approach focuses on a logic of trade-offs.
Lake (2011) in treating hierarchy, networks, and markets not as distinct actors but rather as structural properties of a network of connected states (Kahler 2009). Specifically, we conceptualize hierarchy as a community-level network property that captures the level of inequality of trade within each community. This enables us to explore how hierarchy conditions the relationship between community and conflict. It also provides insight into how the implications of community membership might vary by market context, a topic largely overlooked in the growing literature on community.

For a concrete example of hierarchy within a community, consider again the example of Egypt and Israel. The pattern of behavior we identified above is indicative of more than just the joint production of security; it also represents a hierarchical relationship. Egypt and Israel are much more dependent on American contributions to their security production than the United States is on their efforts or than they are on one another. Moreover, the United States has asymmetric influence over the form of the joint security production, in terms of the types of weapons systems developed and the ability to set other parameters of foreign policy. ${ }^{13}$

We can generalize from this example to our argument using the logic of switching costs. Arms trade itself carries with it high switching costs due to practically expensive shifts in training, maintenance, and equipment, signaling the possibility for underlying constraint. As this example illustrates, hierarchical relationships can further raise these switching costs, particularly for subordinate states. A hierarchy in the trade of heavy arms implies the dominance of a key producer (Caverley 2017). Buyers from that producer may not have any alternative producers available for specific weapons systems to which they have already committed. A less hierarchical armstrading relationship, in contrast, suggests multiple producers and thus relatively cheaper switching costs for the buyers. Switching arms suppliers in a hierarchical context also implies the potential loss of other benefits of being in a shared JPSC with a dominant power, including the provision of security, aid, advising, and the like. The desire to avoid the loss of these benefits increases switching costs and so further increases constraints on states within hierarchical communities. This is consonant with the literature: when less central states face substantial costs for exit from a community dominated by a central state, the central state has substantial leverage (Kahler 2009; Lake 2009). The central state, in turn, can use that leverage to enforce order among the community members. This leads to our second hypothesis:

13. For example, Lin (2012) argues that the United States had used conventional arms transfers as a way to slow down the development of nuclear weapons by recipients, even Israel. 
H2. All else equal, the more hierarchical is a JPSC, the more of a constraining effect on intracommunity conflict it will have.

Two conditions increase the likelihood that our argument and hypothesis hold. One, subordinate states must be receiving the sorts of benefits described above from JPSC membership. Two, superordinate states must have incentive to provide these benefits so as to reduce collective action problems in security provision (Olson and Zeckhauser 1966).

The assumption of concrete benefits for subordinate states in hierarchical relationships is consistent with a broad literature. Scholars such as Wohlforth (1999) have argued that a unipolar system such as that dominated by the United States after the collapse of the Soviet Union can have widespread security benefits for other states. Ikenberry (2009) argues that hegemonic states can lock in an international order through strategic restraint, whereby they set up international institutions that restrain the hegemon so as to get buy in from other states, akin to Lake's relational theory of hierarchy built on social contract theory. Lake and Wong (2009) similarly point to three ways in which a central node in a network might make its exercise of power valuable - and thus reinforcing - to other network members: central nodes can reduce transaction costs for cooperation by setting and enforcing standards, they can provide dispute-resolution services to member states, and they can contribute to the growth of the network.

Undergirding this logic is a sense that the quality of the joint security production actually benefits from the concentration of authority and resources. Keohane (1985) builds on the logic of collective action to argue that in larger groups, a hegemon is often needed in an environment without sufficient institutions in place to sustain cooperation among the members of a group. Otherwise, the free-rider problem is too great. Trusting many other weaker states to come to one's own defense is more daunting than trusting a single strong state. Weaker states thus may find hierarchy an efficient means to enhance deterrence against outside threats. Further, less central states still have some limited ability to exit- - the ties in a JPSC are less fungible, relatively speaking, but are not unbreakable - which limits the ability of dominant states to threaten the security of other community members (Lake and Wong 2009). ${ }^{14}$

In sum, then, subordinate states receive both concrete security benefits by operating within hierarchical JPSCs, as well

14. For example, in the wake of Turkish frustrations with US stances on security issues including American support for Kurdish forces in Syria and accusations that the United States was complicit in the 2016 attempted coup, Turkey has begun exploring a shift away from the United States as its major arms seller, as seen in its purchase of Russian S-400 missiles. The point here is as in some cases more material gains. What about superordinate states? Presumably, they are not asymmetrically helping community members in their security out of altruism but rather in return for an asymmetric ability to control the form of community order. Such states also receive numerous benefits from the maintenance of order in their communities, including reduced uncertainty, greater gains from arms trade, more favorable policies in subordinate states, and coordination on systems and procedures. For example, superordinate states can provide security assistance in the form of joint exercises such as those between the United States and the Republic of Korea - which can help lock in further arms purchases that benefit the relevant industries in the superordinate states.

Moreover, dominant states tend to have myriad vested economic interests and thus myriad potential threats to those interests. Contributing to the community's security helps reduce threats to those interests in two ways. First, it helps defend and deter against belligerents from outside of the community who may disrupt the joint production economy or otherwise pick off weaker allies until just the strong state is left. ${ }^{15}$ Second, dominant states especially benefit from deterring hostility between members of their own community. NATO might have primarily been intended as a check on Soviet aggression, but it also was motivated to help prevent a repeat of war involving Germany. A dominant state's losses from conflict related to investment outputs and gains from trade are compounded when the disruptions involve multiple close partners who also have significant ties with other close partners. For these reasons, dominant states in more hierarchical communities may be more willing to contribute to joint security production.

\section{METHODS AND MEASURES}

To investigate these two hypotheses, we first operationally define both community and hierarchy. We then assess the level of conflict between comembers of the same community compared to noncomembers and whether the relationship between comembership and conflict is conditioned by the level of hierarchy.

that threats to leave a security community can be credible even if quite costly, which provide some constraints against superordinate states overstepping their bounds. Moreover, the Trump administration's explicit support for Saudi Arabia after details emerged regarding the assassination of Jamal Khashoggi-a journalist residing in the United States - in the Saudi consulate in Turkey demonstrates how superordinate states like the United States perceive constraints in severing their security partnerships with subordinate states because of the superordinate's own reliance on the relationship.

15. Of course, the incentive to defend against outside aggression need not translate into less conflict incidence due to the reciprocal threat of hierarchical JPSCs to states outside the community. 


\section{Community detection}

We apply a community detection algorithm using arms transfers to generate time-varying estimates of the JPSCs. The arms transfer data are reported by Stockholm International Peace Research Institute. ${ }^{16}$

As noted above, community detection seeks to partition a network into subgroups that interact more strongly within themselves than outside of themselves. Clustering and partitioning methods have long interested network scientists and are increasingly prominent in political science. Methods such as spectral clustering, hierarchical clustering, and block modeling are some of the most commonly used toolkits for researchers (Fortunato 2010; Fortunato and Hric 2016; Porter et al. 2009). One of the most widely used methods for community detection is based on the modularity measure introduced by Newman and Girvan (2004). The idea behind it is to compare the links within each of a proposed set of communities to those between these communities and find the best partitions by optimizing community distinctions according to the relative total weights of the edges within the communities. Since this method provides a principled way of discovering subgroup structure from rather complex networks and does not require researchers to predetermine the number of clusters, it has attracted many applications in recent political science studies including topics of roll-call voting in Congress (Waugh et al. 2009), legislation cosponsorship networks in Congress (Zhang et al. 2008), European court citation networks on human rights issues (Lupu and Voeten 2012), and community effects on interstate conflict patterns (Cranmer et al. 2015; Lupu and Traag 2013).

While applications of community detection have successfully contributed to the political science literature, some limitations of the original Newman-Girvan definition of modularity have been revealed by recent findings (e.g., its optimization may fail to identify smaller-scale communities; Fortunato and Barthelemy 2007; Good, de Montjoye, and Clauset 2010). Additionally, the Newman-Girvan definition of modularity is not capable of dealing directly with longitudinal data; all it can do is provide multiple snapshots of edge partitions in each time layer, which is often not enough for empirical research where temporal variation in data is both significant and meaningful. The use of arms-trade data requires the use of a new community detection method that can connect arms trade across time to account for the temporal "lumpiness" of the data. Arms transfers between close buyers and suppliers are not consistent, as spikes of activity are followed by troughs of inactivity after a procurement order has been met. The lull in

16. The complete data set that includes all dyadic arms transfers from the year 1960 to 1999 can be found and downloaded at https://www.sipri .org/databases. activity should not be treated the same as an absence of arms transfers between pairs of states that have never traded, since the buyer typically is still dependent on the supplier for parts and maintenance of weapons systems, and the buyer is prone to return to the supplier as upgrades become available. Typical community-detection methods consider each year on its own and so would elide this important point. We view our method as superior for intertemporal community detection, as it does not throw away data that arise from similarities across years that may be substantively meaningful.

Therefore, this study adopts a multilayer modularity method developed by Mucha et al. (2010). As an extension of modularity methods, this multilayer model addresses the issues of resolution limit and temporal variation of communities by incorporating two parameters, $\gamma$ and $\omega$, where $\gamma$ represents a spatial parameter within layers (Reichardt and Bornholdt 2006), and $\omega$ represents a temporal parameter across layers. Figure 1 visualizes the general concept of this method. Whereas Cranmer et al. (2015) employed multilayer modularity to treat multiplex relationships at fixed times, we directly address temporal variation of communities.

The determination of community structure is processed via quality functions to multilayer networks that are defined by (i) a spatial parameter weighting different penalties to community formation within temporal layers and (ii) a temporal coupling parameter linking multiple adjacency matrices across time. The calculation of multilayer modularity $Q_{\text {multilayer }}$ is summarized by the following equation:

$$
Q_{\text {multilayer }}=\frac{1}{2 \mu} \sum_{i j s r}\left[\left(A_{i j s}-\gamma_{s} \frac{k_{i s} k_{j s}}{2 m_{s}}\right) \delta_{s r}+\delta_{i j} C_{j s r}\right] \delta\left(g_{i s}, g_{j r}\right),
$$

where $A_{i j s}$ are the weighted adjacency matrices connecting state $i$ and $j$ in layer $s, \gamma_{s}$ is a spatial resolution parameter, $k_{i s} k_{j s} / 2 m_{s}$ is the corresponding null model in layer $s, C_{j s r}$ is a

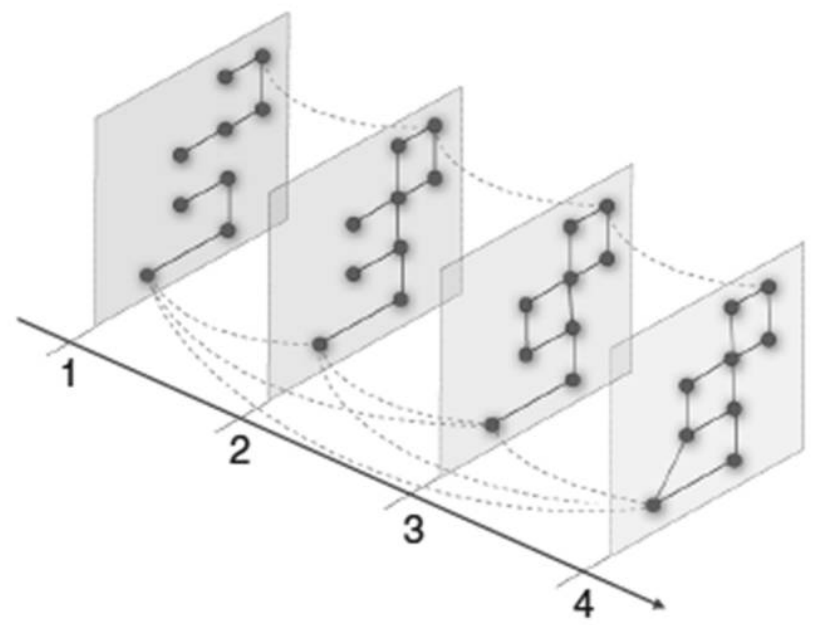

Figure 1. Multilayer community detection. Source: Mucha et al. (2010) 
coupling parameter connecting state $j$ with itself between layers $s$ and $r$ with weight $\omega, g$ is the community assignment of vertex $i$ or $j$ in layer $s$, and Kronecker $\delta$ indicators equal 1 when their two nodes are in the same community.

To calculate the modularity $Q_{\text {multilayer }}$, we started by setting $\gamma=\omega=1$, ran the generalized Louvain code through thousands of runs with pseudorandom vertex orders, and then selected the maximum observed value. ${ }^{17}$ Instead of fixing an arbitrary parameter value and a set of particular community assignments, we scanned through a range of resolution parameters to explore partitions with high and low resolutions and tested our hypotheses against each set of assignments to ensure robustness. Our core results discussed below are robust to each of these resolution specifications. Figure A.1 (figs. A.1A.3 are available online) shows six representative partitions using different parameter levels and the corresponding variation in community assignments across time. ${ }^{18}$ Using this algorithm, the nodes (members of communities) are therefore allowed to transition between communities, or to create new communities based on the observed ties across years, thus incorporating the likelihood of temporal dependence of community membership. This property is particularly useful for the purpose of this study since arms transfers are relatively infrequent occurrences as compared to conventional trade and so have considerable seasonal variation. Without considering community stickiness across time and only partitioning groups based on yearly observations, it is very likely we would dis-

17. This Matlab code can be found at http://netwiki.amath.unc.edu /GenLouvain/GenLouvain.

18. An additional concern in using community detection methods is the discovery of stable communities that are not sensitive to small variations in parameter values. With two parameters to adjust, we sought stable communities by first making $\omega$ large enough to produce nearly constant community assignments across time. Then we generated thousands of partitions by varying the $\gamma$ parameter at that fixed $\omega$ to identify domains of modularity optimization that yielded the most stable communities. Figure A.2a illustrates that we were able to find a band of parameters over which community detection appears to be stable for our arms trade data, as a wider plateau represents a more stable partition under the parameter settings. This postprocessing partition search led us to fix $\gamma=0.5$ and 0.7 . We then used these values to generate community assignments by varying $\omega$ (the temporal coupling parameter). More details on other available postprocessing techniques can be found in Weir et al. (2017). We note that we were somewhat less able to find stable partitions (no apparent wider plateau) in our commercial trade data, as fig. A.2b shows. This is not inconsistent with our theoretical claims as to the relative fungibility of commercial trade ties, relative to arms trade ties. Using the commercial trade data and the postprocessing search, we settled on three different $\gamma$ values $(\gamma=0.7,0.9,1.3)$, which yield four, six, and eight communities on average. The $\omega$ values are set to 1 because commercial trade data do not have much temporal variation and changing the temporal coupling parameter does not yield sufficiently different community partitions. cover false partitions because states are not arms trading with each other regularly in every year.

Figure 2 illustrates a sample of the output of community detection using this multilayer modularity. These are the communities produced for 1999, the last year for which we have data. Three representative partitions - corresponding to high (seven communities), medium (three communities), and low (two communities) resolution levels - are generated by using the $\gamma$ value that yields the most stable partition across time and varying the $\omega$ value to reach different resolution levels. ${ }^{19}$ The maps demonstrate the ability of the algorithm to detect communities different from ones based on simple definitions of regions or formal alliance blocs.

The maps reveal some consistencies across the defined communities - for example, the US community always includes Egypt and Saudi Arabia, and the China community always includes Pakistan, Iran, and Myanmar — but also some inconsistencies as well. Modular approaches to community detection typically will exhibit some variation from run to run as some communities are better defined than others. To account for this inherent uncertainty, we ran the algorithm 100 times at each parameter setting. From these runs, we calculated the empirical probability of each dyad's connecting two nodes in the same community. This probabilistic approach should be more robust than classifying comemberships with a single iteration. For our reported regressions, we consider a dyad to be in a shared community if more than half of these 100 iterations place them together. ${ }^{20}$

\section{Hierarchy measure}

In order to capture hierarchy within communities, we rely on a measure of hierarchy used in the social networks literature that accounts for both the weight and directionality of ties in the network (Mones, Vicsek, and Vicsek 2012). ${ }^{21}$

19. For fig. 2, $\gamma=0.5$ and $\omega=\{1,5,10\}$. We follow Lupu and Traag (2013) in their practice of showing low, medium, and high resolutions to demonstrate the effect of changing parameters on the number of communities detected.

20. As a robustness check, we replicated our results using the precise probability of being in the same community. All results are robust to using this probability instead of dichotomized community membership. We report these analyses in the appendix.

21. While we use a measure of relational power derived from network ties, our conception of hierarchy overlaps with other conceptions of power based on disproportionate military capabilities. The states that are dominant in hierarchical JPSCs are also likely to be the states with the greatest amount of military capabilities. That being said, our regression models control for the bilateral ratio of latent military capabilities, to distinguish the effect of hierarchy from the effects of other manifestations of power imbalance that could exist in the absence of joint community membership and in the absence of hierarchy. 

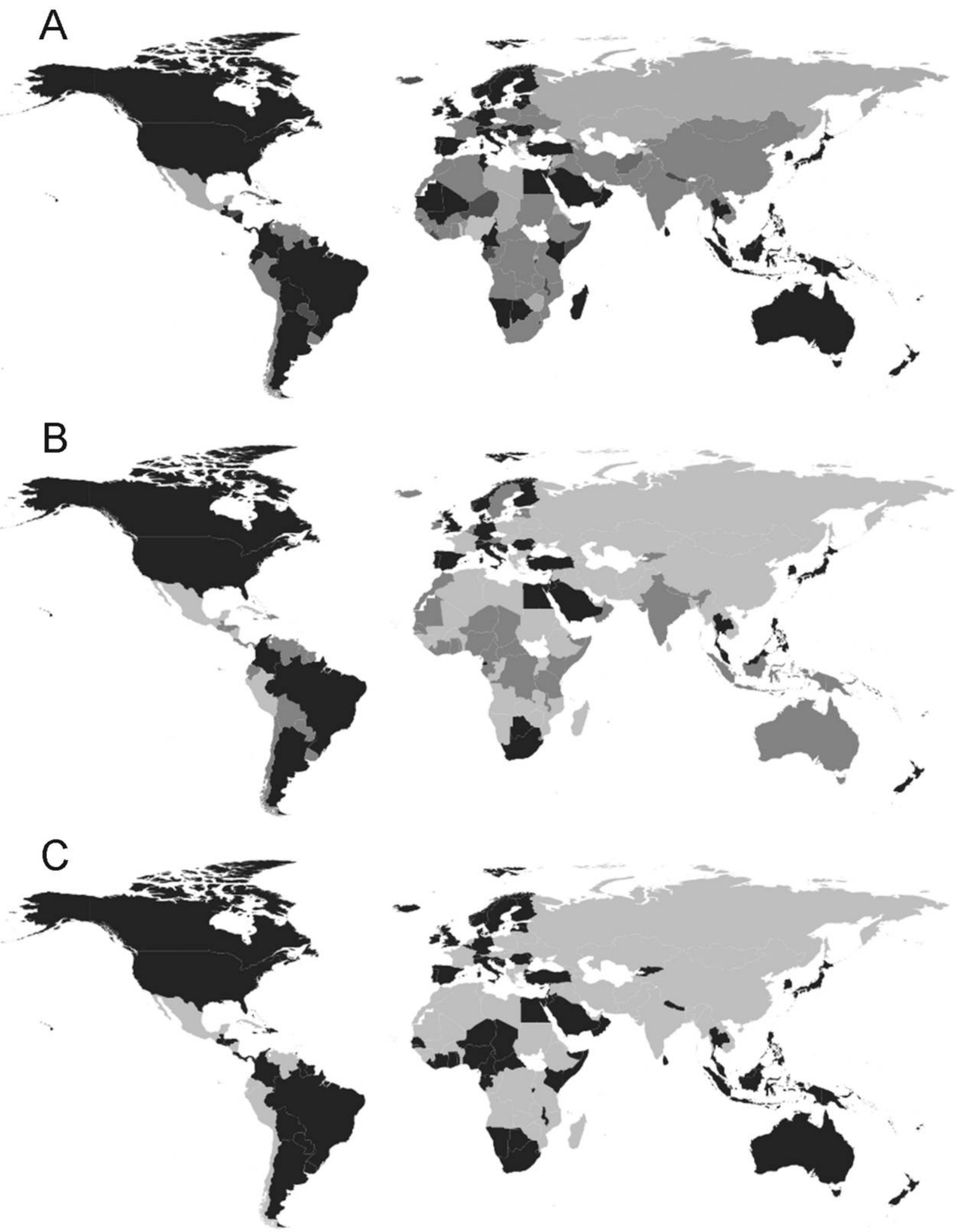

Figure 2. Visualizations of joint-production security communities in 1999 at different resolution levels. A, High resolution (seven communities); $B$, medium resolution (three communities); $\mathrm{C}$, low resolution (two communities). 
This approach takes as a starting point the notion that centrality is often used as a measure of nodal influence in network applications. Nodes (in our case, states) that are more central in a network are more influential than those found in the periphery, which is consistent with the concept of social power developed in previous work (Hafner-Burton and Montgomery 2009; Kahler 2009). A measure of hierarchy within a community should thus capture the degree of influence that each node has within that community. A community where one state is highly central (a "star graph") is more hierarchical than a community where member states share equal centrality.

Toward this end, we follow Mones et al. (2012) and adapt the Global Reaching Centrality (GRC) as a network characteristic that measures hierarchy. GRC takes the following form:

$$
\mathrm{GRC}_{R}=\frac{\sum_{i} C_{R}^{\max }-C_{R}(i)}{N-1} .
$$

Here, we define $C_{R}(i)$ as the closeness centrality score of node $i$ in community $R^{22}$ Since the full network of arms transfers is a disconnected graph (i.e., not all states in the network are connected via arms transfers), we measure closeness centrality using the method described in Opsahl, Agneessens, and Skvoretz (2010) and used in Kinne (2012). ${ }^{23}$ This measure of closeness centrality takes the inverse of the summed shortest paths from a country to all other countries to which it is connected, where the shortest path algorithm accounts for both the weight of the ties (the amount of the transfers) and the number of intermediary nodes. The node with the largest closeness centrality score within $R$ is defined by $C_{R}^{\max }$, and the total number of nodes within a community is defined by $N$.

Thus, $\mathrm{GRC}_{R}$ measures the average distance from each state's centrality score to the maximum centrality score within a given community $R$. Where many states within a community transfer arms, the resulting GRC will be low; in contrast,

22. There are various metrics for centrality that are appropriate in different contexts (Montgomery 2016). We use closeness centrality in our hierarchy calculation because it assigns importance to indirect influence via intermediaries, an important component of our conceptualization of hierarchy. By comparison, degree centrality tends to emphasize only direct influence, while betweenness centrality assigns importance to nodes mediating relationships, rather than nodes that influence both directly and through mediators. As a test of robustness, we replicate the analysis using weighted out-degree in the hierarchy measure. The results are largely consistent (table A.10; tables A.1-A.20 are available online); further, we find the degreeand closeness-centrality based hierarchy measures are highly correlated.

23. Closeness centrality in Opsahl et al. (2010) depends on a tuning parameter $\alpha$, which weights the measure to reflect either the number of trading partners ( $\alpha$ values closer to 0 ) or the depth of trading ties ( $\alpha$ values closer to 1 ). We present results from setting $\alpha$ equal to 1 , although we find results change little when we lower the parameter setting (e.g., setting $\alpha$ to 0.5 ). where one state provides all weapons transfers within a community (a star graph) the GRC will be high. ${ }^{24}$ This captures well our theoretical definition of hierarchy in JPSCs, which focuses on inequality in arms trade across a community. It is also consistent with other approaches that have considered variation in power across network structures (Hafner-Burton and Montgomery 2009; Kahler 2009; Lake and Wong 2009).

We see variation in hierarchy in the 1999 examples depicted in figure 2. At each resolution, the community with the United States is the most hierarchical, which comports well with the perceptions of US hegemony in the postwar era. ${ }^{25}$ Other communities, including rather large communities with China as a member, are flatter. We want to see whether variation in hierarchy conditions the conflict-reducing potential of common community membership. Table A.1 presents other descriptive statistics pertaining to community membership and levels of hierarchy across each of the parameter values.

\section{Regression models}

We use dyad-year data on militarized interstate disputes to assess whether JPSC membership and the level of hierarchy within JPSCs can help explain the propensity for armed conflict between states. Following Lupu and Traag (2013), who examine the relationship between communities of commercial trade and conflict, we estimate the model using logistic regression with a set of control variables. ${ }^{26} \mathrm{We}$ generate standard errors that are robust to clustering on the level of the dyad. We run two models: a base model with JPSC membership but not hierarchy and an interactive model with the low hierarchy score for the dyad interacted with common JPSC membership. We employ logistic regression to fit with prior literature, to enable easier uptake of our results, and because we have a clear argument for how network structure matters. However, we also demonstrate the robustness of our findings across a number of alternative community detection and regression model specifications, including specifications using temporal exponential random graph model (TERGM) and additive and multiplicative effects network (AMEN)

24. As we believe that outside options for sub- (super-) ordinate states will tend to decrease (increase) the ability of the superordinate state to exert constraint on subordinate states, throughout the article we consider a state's arms transfers to every other state in the international system, not just transfers within its own community. However, results are similar if we consider only ties within the community when defining hierarchy (table A.9).

25. See Caverley (2017) for a discussion of extensive US influence via its arms trade. In a robustness check below, we find that the variation in hierarchy is still meaningful even when the communities with the United States are omitted. So, hierarchy is not just a proxy for connectedness to the United States.

26. Results are substantively unchanged if we control for dyad commercial trade dependence. 
approaches that more fully capture network interdependencies (Minhas, Hoff, and Ward 2019).

\section{RESULTS AND DISCUSSION Hierarchy and arms trade}

Figure 3 graphically depicts regression results from the base model, in which we consider only the role of community, absent considerations of hierarchy. It considers only one set of community detection parameter values we explored, but results are similar for others. ${ }^{27}$

The coefficient estimate for the indicator variable capturing whether a given dyad is within the same security community is negative, statistically significant, and, as seen through our standardized coefficients, substantively large. Consistent with our expectations, this suggests that being within the same JPSC decreases the likelihood of conflict between two states, over and above what variation the other variables in the model are able to capture. Importantly, joint community membership has a stronger pacifying effect than bilateral arms transfers. Moreover, the pacifying effect related to the presence of a formal alliance between the states is weaker than that for joint membership in the community - which includes informal alliances and only partially overlaps with formal alliance commitments. Accounting for community membership in the network of arms transfers better explains the potential for armed conflict than the simple level of bilateral arms sales between two states and the presence of a formal alliance, providing support for our first hypothesis.

As a robustness check, we also consider the potential for JPSCs to be defined by explicit defense cooperation agreements, as in Kinne (2017). Like the JPSCs defined by arms transfers, we similarly find that joint membership in JPSCs defined by defense cooperation agreements is associated with less potential for a militarized interstate dispute, even while controlling for the presence of a dyadic defense cooperation agreement. Table A.3 presents the results. ${ }^{28}$

Next we turn to hierarchy and our second hypothesis. Table 1 contains full regression results for six different community detection parameter values. ${ }^{29}$ The table contains several things of note. First, the coefficient on community, now repre-

27. Table A.2 presents conventional regression output for six different sets of community detection parameter values. In addition, the results hold if we use the probability of two states being in the same community instead of a dichotomous indicator of community membership.

28. Following the same postprocessing procedure, we used three $\gamma$ values $(\gamma=0.7,0.9,1)$ that yield four, three, and two communities. The value of $\omega$ was set high $(\omega=100)$ to capture the strong temporal dependence for defense agreements, but varying $\omega$ (the temporal coupling parameter) does not yield appreciably different partition results.

29. The results are robust to using the probability of belonging to the same community instead of a dichotomous indicator.

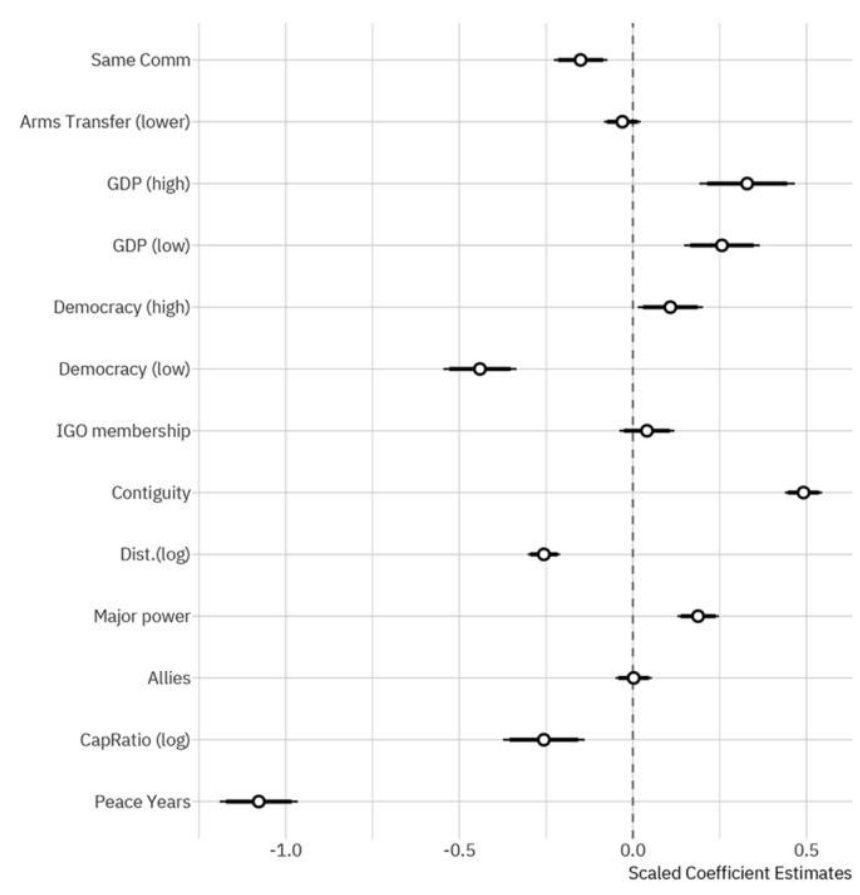

Figure 3. Base model regression results using parameter setting $\omega=1$, $\gamma=0.5$.

senting community in the absence of hierarchy, is not consistently negative. This suggests that community on its own may not be the driving force beyond the pacifying effects of arms trade, since states within "flatter" security communities are not necessarily less prone to conflict with each other than with states outside their community. ${ }^{30}$ This also suggests that our all-else-equal condition in our first hypothesis was perhaps too strong: controlling for hierarchy might be necessary to understand the role of a JPSC in constraining conflict.

Second, consistent with our expectations, the pacifying effect of arms trade is present in communities that are characterized by high levels of hierarchy, and substantially so. With other control variables at their medians, contiguous states that are in the same community with maximum hierarchy have a more than $50 \%$ reduced risk of conflict compared to contiguous states that are not in the same community. Figure 4, a marginal-effects plot, visualizes the interactive effect of community status and community hierarchy in order to make this point. This supports our second hypothesis. ${ }^{31}$

Third, the conditioning effect of hierarchy appears consistent across community detection parameter values. This provides significant confidence in our inferences, in that this

30. We ran additional analyses using some common network models. Tables A.13-A.20 show that results are largely consistent when we use TERGM and AMEN models.

31. While our primary goal is not prediction, we also evaluate out-ofsample prediction using the network variables. We find that including the network variables marginally improves predictive performance. 
Table 1. Interstate Arms Trade: Hierarchy Models

\begin{tabular}{|c|c|c|c|c|c|c|}
\hline & \multicolumn{3}{|c|}{ Low Spatial Resolution } & \multicolumn{3}{|c|}{ High Spatial Resolution } \\
\hline & Low TR & Medium TR & High TR & Low TR & Medium TR & High TR \\
\hline Intercept & $\begin{array}{c}-6.582^{\star * *} \\
(.425)\end{array}$ & $\begin{array}{c}-6.778^{\star * *} \\
(.441)\end{array}$ & $\begin{array}{c}-6.759^{* * *} \\
(.450)\end{array}$ & $\begin{array}{c}-6.488^{\star * *} \\
(.401)\end{array}$ & $\begin{array}{c}-6.505^{\star * *} \\
(.420)\end{array}$ & $\begin{array}{c}-6.267^{\star * *} \\
(.385)\end{array}$ \\
\hline Same community & $\begin{array}{c}.237 \\
(.246)\end{array}$ & $\begin{array}{c}.371 \\
(.270)\end{array}$ & $\begin{array}{r}.493^{\star} \\
(.281)\end{array}$ & $\begin{array}{c}.214 \\
(.210)\end{array}$ & $\begin{array}{c}-.203 \\
(.261)\end{array}$ & $\begin{array}{r}-.361^{\star} \\
(.201)\end{array}$ \\
\hline Hierarchy (lower) & $\begin{array}{l}.004^{* * *} \\
(.001)\end{array}$ & $\begin{array}{l}.004^{* * *} \\
(.001)\end{array}$ & $\begin{array}{l}.004^{* * *} \\
(.001)\end{array}$ & $\begin{array}{l}.004^{\star * *} \\
(.001)\end{array}$ & $\begin{array}{l}.003^{* * *} \\
(.001)\end{array}$ & $\begin{array}{l}.003^{* * *} \\
(.001)\end{array}$ \\
\hline Arms transfer (lower) & $\begin{array}{r}-.019 \\
(.017)\end{array}$ & $\begin{array}{c}-.019 \\
(.017)\end{array}$ & $\begin{array}{r}-.019 \\
(.017)\end{array}$ & $\begin{array}{c}-.019 \\
(.017)\end{array}$ & $\begin{array}{r}-.020 \\
(.017)\end{array}$ & $\begin{array}{r}-.021 \\
(.017)\end{array}$ \\
\hline GDP (high) & $\begin{array}{l}.155^{* * *} \\
(.044)\end{array}$ & $\begin{array}{l}.158^{* * *} \\
(.044)\end{array}$ & $\begin{array}{l}.162^{* * *} \\
(.044)\end{array}$ & $\begin{array}{l}.157^{* * *} \\
(.044)\end{array}$ & $\begin{array}{l}.153^{* * *} \\
(.043)\end{array}$ & $\begin{array}{l}.147^{* * *} \\
(.043)\end{array}$ \\
\hline GDP (low) & $\begin{array}{l}.084^{\star *} \\
(.041)\end{array}$ & $\begin{array}{l}.093^{\star *} \\
(.041)\end{array}$ & $\begin{array}{l}.088^{\star *} \\
(.041)\end{array}$ & $\begin{array}{c}.080^{\star} \\
(.042)\end{array}$ & $\begin{array}{l}.092^{\star \star} \\
(.041)\end{array}$ & $\begin{array}{l}.081^{\star *} \\
(.041)\end{array}$ \\
\hline Democracy (high) & $\begin{array}{l}.024^{\star} \\
(.014)\end{array}$ & $\begin{array}{l}.025^{\star} \\
(.014)\end{array}$ & $\begin{array}{c}.024^{\star} \\
(.014)\end{array}$ & $\begin{array}{c}.025^{\star} \\
(.014)\end{array}$ & $\begin{array}{c}.024^{\star} \\
(.014)\end{array}$ & $\begin{array}{c}.022 \\
(.014)\end{array}$ \\
\hline Democracy (low) & $\begin{array}{c}-.126^{\star * *} \\
(.022)\end{array}$ & $\begin{array}{c}-.129^{\star * *} \\
(.022)\end{array}$ & $\begin{array}{c}-.124^{\star * \star} \\
(.022)\end{array}$ & $\begin{array}{c}-.125^{\star * *} \\
(.023)\end{array}$ & $\begin{array}{c}-.126^{\star * *} \\
(.022)\end{array}$ & $\begin{array}{c}-.131^{\star * *} \\
(.023)\end{array}$ \\
\hline IGO membership & $\begin{array}{c}.006 \\
(.005)\end{array}$ & $\begin{array}{c}.006 \\
(.005)\end{array}$ & $\begin{array}{l}.006 \\
(.005)\end{array}$ & $\begin{array}{c}.006 \\
(.005)\end{array}$ & $\begin{array}{c}.005 \\
(.005)\end{array}$ & $\begin{array}{l}.006 \\
(.005)\end{array}$ \\
\hline Contiguity & $\begin{array}{l}2.565^{\star * *} \\
(.256)\end{array}$ & $\begin{array}{l}2.595^{\star * *} \\
(.260)\end{array}$ & $\begin{array}{l}2.560^{* * *} \\
(.257)\end{array}$ & $\begin{array}{l}2.549^{\star * *} \\
(.256)\end{array}$ & $\begin{array}{l}2.567^{\star * *} \\
(.259)\end{array}$ & $\begin{array}{l}2.566^{\star * *} \\
(.256)\end{array}$ \\
\hline Distance (log) & $\begin{array}{c}-.184^{\star * *} \\
(.025)\end{array}$ & $\begin{array}{c}-.180^{\star * \star} \\
(.026)\end{array}$ & $\begin{array}{c}-.183^{\star * *} \\
(.025)\end{array}$ & $\begin{array}{c}-.185^{\star \star \star} \\
(.025)\end{array}$ & $\begin{array}{c}-.186^{* * *} \\
(.026)\end{array}$ & $\begin{array}{c}-.184^{\star * \star} \\
(.025)\end{array}$ \\
\hline Major power & $\begin{array}{l}.785^{\star * *} \\
(.176)\end{array}$ & $\begin{array}{l}.759^{\star \star \star} \\
(.176)\end{array}$ & $\begin{array}{l}.759^{\star \star \star} \\
(.176)\end{array}$ & $\begin{array}{l}.784^{\star * *} \\
(.176)\end{array}$ & $\begin{array}{l}.794^{\star \star *} \\
(.177)\end{array}$ & $\begin{array}{l}.826^{\star * *} \\
(.177)\end{array}$ \\
\hline Allies & $\begin{array}{c}.049 \\
(.150)\end{array}$ & $\begin{array}{c}.043 \\
(.150)\end{array}$ & $\begin{array}{c}.065 \\
(.149)\end{array}$ & $\begin{array}{c}.046 \\
(.148)\end{array}$ & $\begin{array}{c}.047 \\
(.151)\end{array}$ & $\begin{array}{c}.010 \\
(.148)\end{array}$ \\
\hline Capability ratio $(\log )$ & $\begin{array}{c}-.131^{\star * *} \\
(.043)\end{array}$ & $\begin{array}{c}-.126^{\star * *} \\
(.043)\end{array}$ & $\begin{array}{c}-.129^{\star * \star} \\
(.043)\end{array}$ & $\begin{array}{c}-.133^{\star * *} \\
(.043)\end{array}$ & $\begin{array}{c}-.126^{* * *} \\
(.042)\end{array}$ & $\begin{array}{c}-.132^{\star * *} \\
(.042)\end{array}$ \\
\hline Peace years & $\begin{array}{c}-.334^{* * *} \\
(.029)\end{array}$ & $\begin{array}{c}-.332^{* * *} \\
(.029)\end{array}$ & $\begin{array}{c}-.334^{* * *} \\
(.029)\end{array}$ & $\begin{array}{c}-.334^{* * *} \\
(.030)\end{array}$ & $\begin{array}{c}-.331^{* * *} \\
(.030)\end{array}$ & $\begin{array}{c}-.335^{\star * *} \\
(.029)\end{array}$ \\
\hline Same community $\times$ hierarchy & $\begin{array}{c}-.004^{* * *} \\
(.001)\end{array}$ & $\begin{array}{c}-.004^{* * *} \\
(.001)\end{array}$ & $\begin{array}{c}-.005^{\star * *} \\
(.001)\end{array}$ & $\begin{array}{c}-.004^{* * *} \\
(.001)\end{array}$ & $\begin{array}{c}-.002 \\
(.001)\end{array}$ & $\begin{array}{c}-.0004 \\
(.001)\end{array}$ \\
\hline
\end{tabular}

Note. Standard errors in parentheses. TR $=$ temporal resolution; GDP $=$ gross domestic product; IGO $=$ intergovernmental organization. $N=390,914$. ${ }^{*} p<.1$.

${ }^{* *} p<.05$.

*** $p<.01$.

range of parameter values produces anywhere from two to 10 different communities in the world system. Regardless of how finely states are grouped, the same substantive effect holds: hierarchical arms trade communities pacify. ${ }^{32}$

Finally, note that our argument, based on the degree to which stronger states can influence weaker ones to act in accordance

32. As a test of robustness, we also replicate the analysis by aggregating to the community level and testing whether more hierarchical communities tend to have less conflict. The results are qualitatively similar, although some estimates do not reach conventional significance levels given the radically reduced sample size (table A.11). with stronger states' desires, makes no claim on intercommunity conflict. Dominant states in more hierarchical communities may be better able to defend community members, but such communities might be more threatening to other communities. The results indicate that the coefficient on hierarchy - the lower hierarchy score in each dyad - is significant and positive, showing greater conflict between more hierarchical communities. This intercommunity finding corroborates in some ways existing understandings of international politics. Since more hierarchical communities better serve the dominant actor, they may induce a greater threat to strong external states, increasing the potential for conflict 


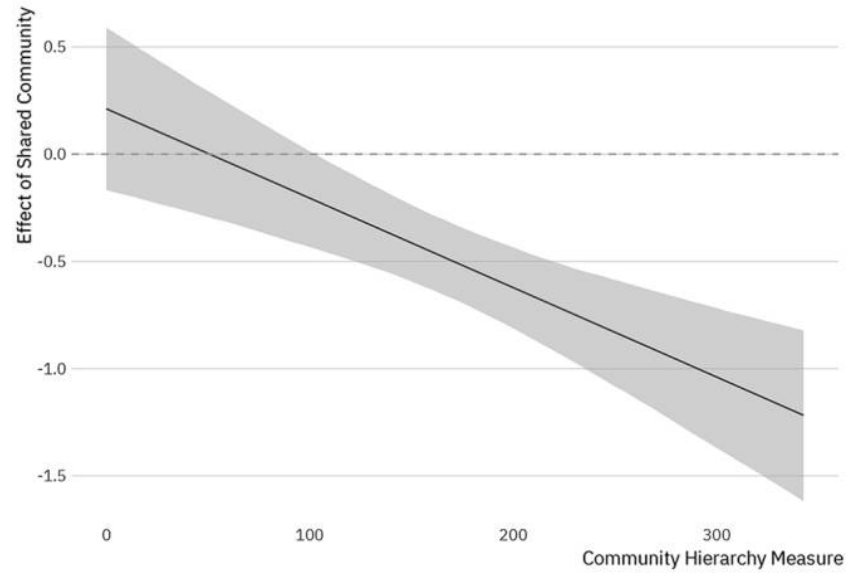

Figure 4. Same-community effect as community hierarchy increases. Parameters: $\omega=1, \gamma=0.5$

between central actors via a security dilemma logic. And if strong states are more likely to engage in conflict themselves, members of the hierarchical communities they lead will more easily be drawn into the conflict via a chain-ganging logic. Moreover, dominant states of different communities in dispute with one another have an incentive for the dispute to play out by proxy through confrontation between their subordinate states.

To further parse our results, we conducted a series of additional exploratory analyses. In the first, we find that the interactive effect of hierarchy and common-community membership only helps explain the reduction in conflict between subordinate states in the same community and not as well the reduction between dominant and subordinate states. Tables A. 4 and A.5 decompose the common-community variable into "flat" comembership (when both states are not the most central state) and "imbalanced" comembership (when one of the states is the most central). We see that the negative effect of comembership in the presence of hierarchy is driven by the flat comembers. The implication becomes clearer when considering the finding from the main models that the relationship between dyadic arms-transfer volume and conflict is not statistically significant: it is not dyadic trade between flat comembers that reduces conflict but rather the constraints on their behavior induced by trade with the dominant state. This provides further support for our argument regarding the conflict-reducing potential of hierarchy. It is not merely that dominant states limit conflict between themselves and weaker states; rather, dominant states in hierarchical communities reduce conflict between nondominant members of their communities via the exertion of leverage enabled by high switching costs. $^{33}$

33. If hierarchy is based on legitimate authority, or more generally if JPSC structure is in equilibrium, the use of conflict by dominant states
In the second, we considered the potential for the effect of hierarchy to be solely driven by relationships with the United States. Existing scholarship has well explored US efforts in the post-World War II era to promote peace in its spheres of influence (see, e.g., Ikenberry 2009; Lake 1999, 2009). In separate analyses, shown in table A.6, we exclude the states that are in the same community as the United States and still find that hierarchy enhances the extent to which JPSC comembership reduces the potential for conflict.

Overall, the results on arms trade networks confirm that JPSC membership and hierarchy within JPSCs help explain the occurrence of conflict in the international system. Jointproduction security community membership and the level of hierarchy capture the underlying web of constraints. Arms trade, by enabling relatively strong influence of central states over noncentral states because of high switching costs, is able to pacify within trading communities, past a sufficient level of hierarchy. Without this level of hierarchy, there is not the necessary source of constraint. This suggests again the importance of the concept of switching costs, which vary in hierarchy and enable constraint.

\section{Hierarchy and interstate commercial trade}

As further support for the centrality of a switching cost logic, we repeat the same core analyses on commercial, rather than arms, trade (Lupu and Traag 2013). As noted above, we expect that, on average, switching costs will be lower in commercial trade, leading to less constraint and so less of a role for commercial trade communities as pacifying agents. Further, as the role of hierarchy in security provision does not readily translate to commercial hierarchies, we do not expect hierarchy to play the same role in commercial trade networks.

Figure 5 presents results from the base model regressions, following the same procedure as above in determining interstate commercial trade community membership. ${ }^{34}$ We note immediately the major difference between the effect of commercial and arms trade communities: whereas we found pacifying effects of arms trade community membership, we find increased propensity for conflict as a function of belonging to the same commercial trade community. This is true across a range of parameter values, as can be seen in table A.7. ${ }^{35}$

against subordinate states should be rare. That being said, failure of dominant states to keep subordinate states in line will erode the level of legitimacy and authority that the dominant state has, and so we should expect to observe some level of corrective measures by dominant states among members of their security communities, as observed in the Soviet treatment of uprisings in Hungary (1956) and Czechoslovakia (1968).

34. Figure 5 leaves out the coefficients on peace years and the three splines for presentation purposes.

35. This result is consistent with the erratum to Lupu and Traag (2013) posted at https://github.com/vtraag/trading-communities-replication. 


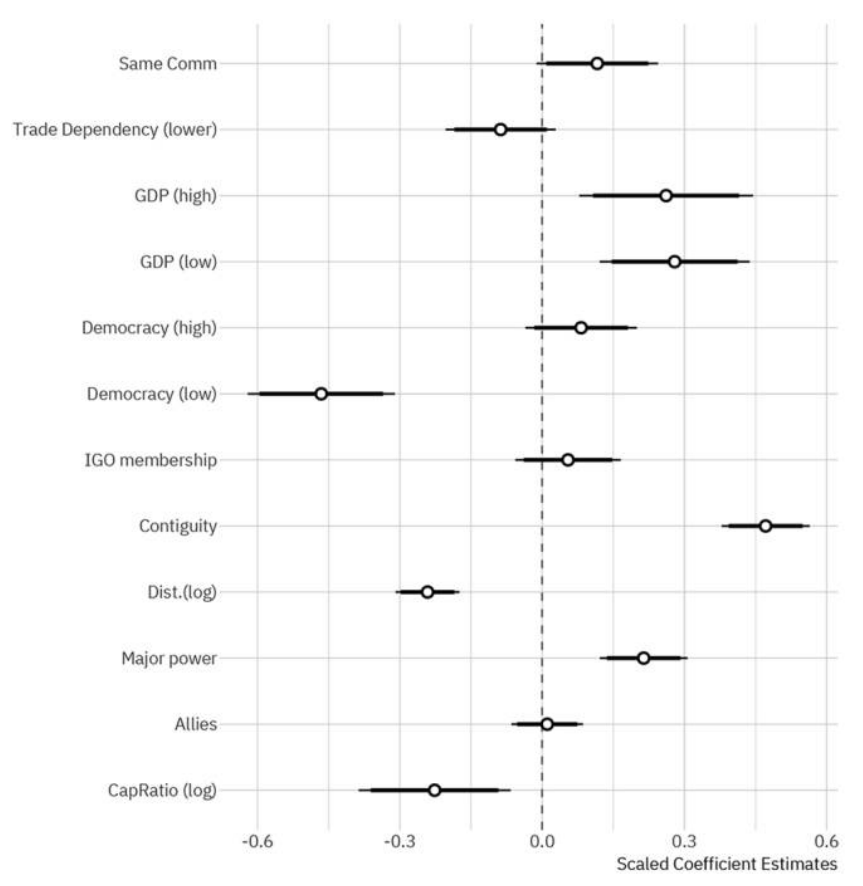

Figure 5. Base model regression for commercial trade data

We calculate community hierarchy scores based on the dyadic trade dependence measure provided by Oneal and Russet (1997). Table A.8 indicates that the interaction of hierarchy and same community membership is not statistically significant for any parameterization; the sign on the interaction is also inconsistent across parameterizations. Further, even when we choose a parameterization that produces a negative sign on the interaction coefficient, as in the JPSC analysis, the marginal effect of community membership is never significantly different from zero at any level of hierarchy, as seen in figure 6.

Thus, it appears that our expectation on the importance of switching costs is supported: not only do the more fungible commercial-trade communities fail to pacify, but we generally observe more conflict within commercial-trade communities. From existing theory we might expect that this is due to the more frequent interactions within commercialtrade communities, coupled with an inability of even central states to impose order. This inability comes not because of an absence of hierarchy as measured by asymmetry in commercial trade but rather because of decreased switching costs, which diminish the power of leading states to constrain. If this conjecture were true, we would not expect to see a consistent pacifying role of hierarchy. This is what we find. Stronger states are simply less able to compel weaker states within their communities when weaker states are more free to break old ties and make new ones.

\section{CONCLUSION}

We conceptualize hierarchy and community as two properties of network structure; together, they capture aspects of the underlying web of interests and constraints that drive interstate behavior. We bring to the discipline a new use of community detection for temporal data and a new measure of hierarchy within communities to show that common membership in JPSCs leads to a reduction in conflict between states in the international system. In other words, arms trade, from which we constructed our JPSCs, can pacify. This is more true the more hierarchical are the JPSCs, and is not explained merely by dyadic trade ties. This result also does not arise solely from the presence of a common external threat: more hierarchical JPSCs exhibit more, not less, conflict between communities.

We argue that arms-trade communities have this intracommunity pacifying effect, in part, because of the presence of switching costs. States suffer many kinds of costs from switching their suppliers of heavy arms and suffer additional costs when these are strong states that are the only suppliers of specific weapons systems and that can provide other benefits to weaker states. The existence of these costs provides leverage to stronger states, which translates to constraints on weaker states' conflict behavior. We show that the same argument fails for communities constructed from commercial trade networks: commercial trade, on average, is more fungible than heavy arms trade and so produces neither strong constraints nor pacification.

Future extensions of our approach might include multiple inputs into the detection of the JPSCs - not only arms transfers but also formal alliances, troop deployments, defense cooperation agreements, diplomatic ties, and so on. That our JPSCs defined only with arms transfers do not cleanly overlap with regional orders or alliance blocs attests to the merit of

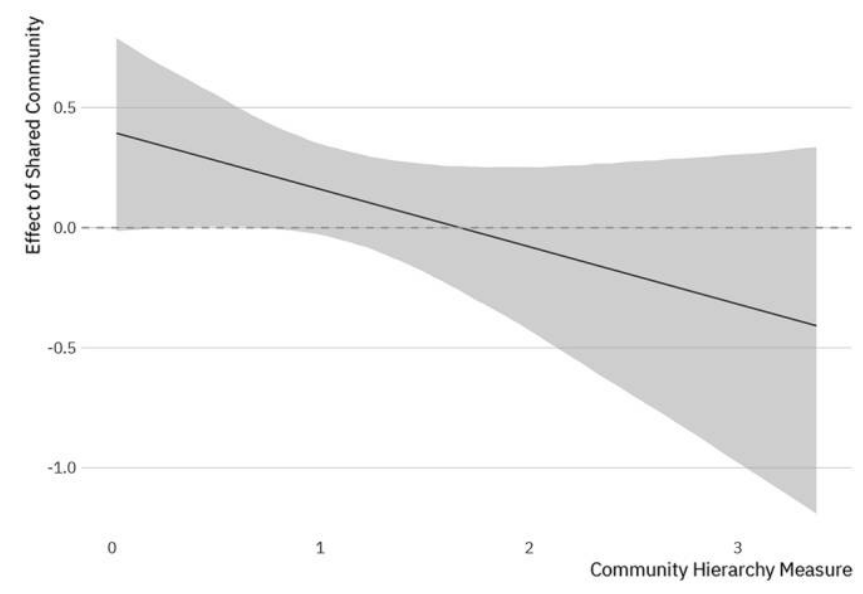

Figure 6. Same-community effect as community hierarchy increases for commercial trade. 
considering arms transfers as an indicator of joint security production. Many other measures would miss important security cooperation among, say, the United States, Egypt, and Israel. That said, arms transfers are an imperfect measure alone, and it would be useful to consider additional information on joint security production.

We also plan to expand on our theory as to how communities affect conflict and cooperation. For example, a full causal mediation model that connects JPSC membership and hierarchy to foreign policy alignment would add to our understanding of the manner in which interdependent interactions between states condition state behavior. Even more ambitious would be the construction of a theoretical and empirical model that allows JPSCs at different levels of hierarchy to emerge endogenously from a network of conflict and cooperation and to allow the JPSCs to shape the network in turn.

\section{ACKNOWLEDGMENTS}

The authors would like to thank David Lake; Brandon Kinne; Jonatan Lupu; Vincent Traag; the participants at the University of California, Berkeley, MIRTH seminar, especially Michaela Mattes, Aila Mattanock, and Susan Hyde; participants at the Modeling Spatial and Network Interdependence in International Relations workshop at the 2018 International Studies Association annual conference in San Francisco, especially Emily Ritter, Kristian Gleditsch, and Jos Elkink; and participants of the SPC Lab at Duke. We also appreciate William Reed and three anonymous reviewers for their helpful comments.

\section{REFERENCES}

Adler, Emanuel, and Michael N. Barnett. 1998. Security Communities, vol. 62. Cambridge: Cambridge University Press.

Barbieri, Katherine. 1996. "Economic Interdependence: A Path to Peace or a Source of Interstate Conflict?" Lournal of Peace Research 33 (1): $29-49$.

Barbieri, Katherine. 2002. The Liberal Illusion: Does Trade Promote Peace? Ann Arbor: University of Michigan Press.

Bearce, David H., Kristen M. Flanagan, and Katharine M. Floros. 2006 "Alliances, Internal Information, and Military Conflict among MemberStates.” International Organization 60 (3): 595-625.

Brauer, Jurgen. 2003. "Potential and Actual Arms Production: Implications for the Arms Trade Debate." In Paul Levine and Ron Smith, eds., Arms Trade, Security, and Conflict. London: Routledge, 21-39.

Caverley, Jonathan D. 2017. "Slowing the Proliferation of Major Conventional Weapons: The Virtues of an Uncompetitive Market." Ethics and International Affairs 31 (4): 401-18.

Cornish, Paul. 1996. Controlling the Arms Trade: The West versus the Rest. London: Bowerdean.

Cranmer, Skyler J., and Bruce A. Desmarais. 2016. "A Critique of Dyadic Design.” International Studies Quarterly 60 (2): 355-62.

Cranmer, Skyler J., Bruce A. Desmarais, and Justin H. Kirkland. 2012. “Toward a Network Theory of Alliance Formation." International Interactions 38 (3): 295-324.
Cranmer, Skyler J., Elizabeth J. Menninga, and Peter J. Mucha. 2015. "Kantian Fractionalization Predicts the Conflict Propensity of the International System." Proceedings of the National Academy of Sciences 112 (38): 11812-16.

Deutsch, Karl W., Sidney A. Burrell, Robert A. Kann, Maurice Lee Jr., Martin Lichterman, Raymond E. Lindgren, Francis L. Loewenheim, and Richard W. Van Wagenen. 1957. Political Community and the North Atlantic Area. Princeton, NJ: Princeton University Press.

Dorff, Cassy, and Michael D. Ward. 2013. "Networks, Dyads, and the Social Relations Model." Political Science Research and Methods 1 (2): 159-78.

Fang, Songying, Jesse C. Johnson, and Brett Ashley Leeds. 2014. "To Concede or to Resist? The Restraining Effect of Military Alliances." International Organization 68 (4): 775-809.

Fortunato, Santo. 2010. "Community Detection in Graphs." Physics Reports 486 (3): 75-174.

Fortunato, Santo, and Marc Barthelemy. 2007. "Resolution Limit in Community Detection." Proceedings of the National Academy of Sciences 104 (1): 36-41.

Fortunato, Santo, and Darko Hric. 2016. "Community Detection in Networks: A User Guide.” Physics Reports 659:1-44.

Gartzke, Erik. 2007. "The Capitalist Peace." American Journal of Political Science 51 (1): 166-91.

Good, Benjamin H., Yves-Alexandre de Montjoye, and Aaron Clauset. 2010. "Performance of Modularity Maximization in Practical Contexts." Physical Review E 81 (4): 046106.

Greenhill, Brian, and Yonatan Lupu. 2017. "Clubs of Clubs: Fragmentation in the Network of Intergovernmental Organizations." International Studies Quarterly 61 (1): 181-95.

Hafner-Burton, Emilie M., and Alexander H. Montgomery. 2009. “Globalization and the Social Power Politics of International Economic Networks." In Miles Kahler, ed., Networked Politics: Agency, Power, and Governance. Ithaca, NY: Cornell University Press, 23-42.

Hegre, Håvard, John R. Oneal, and Bruce Russett. 2010. “Trade Does Promote Peace: New Simultaneous Estimates of the Reciprocal Effects of Trade and Conflict." Journal of Peace Research 47 (6): 763-74.

Hoff, Peter D., and Michael D. Ward. 2004. "Modeling Dependencies in International Relations Networks.” Political Analysis 12 (2): 160-75.

Ikenberry, G. John. 2009. After Victory: Institutions, Strategic Restraint, and the Rebuilding of Order after Major Wars. Princeton, NJ: Princeton University Press.

Jung, Danielle F., and David A. Lake. 2011. "Markets, Hierarchies, and Networks: An Agent-Based Organizational Ecology.” American Journal of Political Science 55 (4): 972-90.

Kahler, Miles. 2009. "Networked Politics: Agency, Power, and Governance.” In Miles Kahler, ed., Networked Politics: Agency, Power, and Governance. Ithaca, NY: Cornell University Press, 1-22.

Keller, William W. 1995. Arm in Arm: The Political Economy of the Global Arms Trade. New York: Basic.

Keohane, Robert O. 1985. After Hegemony: Cooperation and Discord in the World Political Economy. Princeton, NJ: Princeton University Press.

Kinne, Brandon J. 2012. "Multilateral Trade and Militarized Conflict: Centrality, Openness, and Asymmetry in the Global Trade Network." Lournal of Politics 74 (1): 308-22.

Kinne, Brandon J. 2013. "Network Dynamics and the Evolution of International Cooperation.” American Political Science Review 107 (4): 766-85.

Kinne, Brandon J. 2014. "Does Third-Party Trade Reduce Conflict? Credible Signaling versus Opportunity Costs." Conflict Management and Peace Science 31 (1): 28-48.

Kinne, Brandon J. 2016. "Agreeing to Arm: Bilateral Weapons Agreements and the Global Arms Trade." Iournal of Peace Research 53 (3): 359-77. 
Kinne, Brandon J. 2017. "Defense Cooperation Agreements and the Emergence of a Global Security Network." International Organization 72 (4): 799-837.

Kinsella, David. 1998. "Arms Transfer Dependence and Foreign Policy Conflict." Journal of Peace Research 35 (1): 7-23.

Kinsella, David, and Alexander H. Montgomery. 2016. "Arms Supply and Proliferation Networks." In Jennifer N. Victor, Alexander H. Montgomery, and Mark Lubell, eds., Oxford Handbook of Political Networks. New York: Oxford University Press.

Lake, David A. 1999. Entangling Relations: American Foreign Policy in Its Century. Princeton, NJ: Princeton University Press.

Lake, David A. 2009. Hierarchy in International Relations. Ithaca, NY: Cornell University Press.

Lake, David A., and Wendy H. Wong. 2009. "The Politics of Networks: Interests, Power, and Human Rights Norms." In Miles Kahler, ed., Networked Politics: Agency, Power, and Governance. Ithaca, NY: Cornell University Press, 127-50.

Lin, Yang Bonny. 2012. Arms, Alliances, and the Bomb: Using Conventional Arms Transfers to Prevent Nuclear Proliferation. New Haven, CT: Yale University Press.

Long, Andrew G., Timothy Nordstrom, and Kyeonghi Baek. 2007. "Allying for Peace: Treaty Obligations and Conflict between Allies." Lournal of Politics 69 (4): 1103-17.

Lupu, Yonatan, and Vincent A. Traag. 2013. "Trading Communities, the Networked Structure of International Relations, and the Kantian Peace." Journal of Conflict Resolution 57 (6): 1011-42.

Lupu, Yonatan, and Erik Voeten. 2012. "Precedent in International Courts: A Network Analysis of Case Citations by the European Court of Human Rights." British Journal of Political Science 42 (2): 413-39.

Mansfield, Edward D., and Jon C. Pevehouse. 2000. "Trade Blocs, Trade Flows, and International Conflict." International Organization 54 (4): 775-808.

Markusen, Ann. 2004. “Arms Trade as Illiberal Trade.” In Jurgen Brauer and J. Paul Dunne, eds., Arms Trade and Economic Development: Theory, Policy, and Cases in Arms Trade Offsets. London: Routledge, 6688.

Mattern, Janice Bially, and Ayse Zarakol. 2016. "Hierarchies in World Politics." International Organization 70 (3): 623-54.

Mattes, Michaela, and Greg Vonnahme. 2010. "Contracting for Peace: Do Nonaggression Pacts Reduce Conflict?” Lournal of Politics 72 (4): 925 38.

Minhas, Shahryar, Peter D. Hoff, and Michael D. Ward. 2019. "Inferential Approaches for Network Analyses: AMEN for Latent Factor Models." Political Analysis 27 (2): 208-22.

Mones, Enys, Lilla Vicsek, and Tamás Vicsek. 2012. "Hierarchy Measure for Complex Networks.” PloS One 7 (3): e33799.

Montgomery, Alexander. 2016. "Centrality in Transnational Governance: How Networks of International Institutions Shape Power Processes." In Deborah Avant and Oliver Westerwinter, eds., The New Power Politics: Networks and Transnational Security Governance. Oxford: Oxford University Press.

Morrow, James D. 1999. "How Could Trade Affect Conflict?" Lournal of Peace Research 36 (4): 481-89.

Mucha, Peter J., Thomas Richardson, Kevin Macon, Mason A. Porter, and Jukka-Pekka Onnela. 2010. "Community Structure in Time-Dependent, Multiscale, and Multiplex Networks.” Science 328 (5980): 876-78.
Newman, Mark E. J., and Michelle Girvan. 2004. "Finding and Evaluating Community Structure in Networks." Physical Review E 69 (2): 026113.

Olson, Mancur, and Richard Zeckhauser. 1966. "An Economic Theory of Alliances." Review of Economics and Statistics 48 (3): 266-79.

Oneal, John R., and Bruce M. Russet. 1997. "The Classical Liberals Were Right: Democracy, Interdependence, and Conflict, 1950-1985.” International Studies Quarterly 41 (2): 267-94.

Opsahl, Tore, Filip Agneessens, and John Skvoretz. 2010. "Node Centrality in Weighted Networks: Generalizing Degree and Shortest Paths." Social Networks 32 (3): 245-51.

Pauls, Scott D., and Skyler J. Cranmer. 2017. "Affinity Communities in United Nations Voting: Implications for Democracy, Cooperation, and Conflict." Physica A 484:428-39.

Porter, Mason A., Jukka-Pekka Onnela, and Peter J. Mucha. 2009. "Communities in Networks." Notices of the AMS 56 (9): 1082-97, 1164-66.

Pressman, Jeremy. 2008. Warring Friends: Alliance Restraint in International Politics. Ithaca, NY: Cornell University Press.

Reichardt, Jorg, and Stefan Bornholdt. 2006. "Statistical Mechanics of Community Detection.” Phvsical Review E 74 (1): 016110-14.

Smith, Alastair. 1995. "Alliance Formation and War." International Studies Quarterly 39 (4): 405-25.

Snyder, Glenn H. 1984. "The Security Dilemma in Alliance Politics." World Politics 36 (4): 461-95.

Snyder, Glenn H. 2007. Alliance Politics. Ithaca, NY: Cornell University Press.

Starr, Harvey. 2002. "Opportunity, Willingness and Geographic Information Systems (GIS): Reconceptualizing Borders in International Relations." Political Geography 21 (2): 243-61.

Stohl, Rachel, and Suzette Grillot. 2009. The International Arms Trade. Cambridge: Polity.

Thurner, Paul W., Christian S. Schmid, Skyler J. Cranmer, and Göran Kauermann. 2019. "Network Interdependencies and the Evolution of the International Arms Trade." Lournal of Conflict Resolution 63 (7): 1736-64.

Walt, Stephen M. 1990. The Origins of Alliance. Ithaca, NY: Cornell University Press.

Warren, T. Camber. 2010. "The Geometry of Security: Modeling Interstate Alliances as Evolving Networks.” Iournal of Peace Research 47 (6): 697 709.

Warren, T. Camber. 2016. "Modeling the Coevolution of International and Domestic Institutions: Alliances, Democracy, and the Complex Path to Peace." Iournal of Peace Research 53 (3): 424-41.

Waugh, Andrew Scott, Liuyi Pei, James H. Fowler, Peter J. Mucha, and Mason Alexander Porter. 2009. "Party Polarization in Congress: A Network Science Approach." arXiv.org, Cornell University. https://arxiv.org /abs/0907.3509.

Weir, William H., Scott Emmons, Ryan Gibson, Dane Taylor, and Peter J. Mucha. 2017. "Post-processing Partitions to Identify Domains of Modularity Optimization." Algorithms 10 (3): 93.

Weitsman, Patricia A. 2004. Dangerous Alliances: Proponents of Peace, Weapons of War. Palo Alto, CA: Stanford University Press.

Wohlforth, William C. 1999. "The Stability of a Unipolar World." International Security 24 (1): 5-41.

Zhang, Yan, Andrew J. Friend, Amanda L. Traud, Mason A. Porter, James H. Fowler, and Peter J. Mucha. 2008. "Community Structure in Congressional Cosponsorship Networks.” Phvsica A 387 (7): 1705-12. 